\title{
Videothoracoscopic extrapleural insertion of Walter Lorenz Surgical bar for pectus excavatum
}

Helena Hernández, MD, Andres Varela, PhD, Mar Cordoba, MD, Luis Madrigal, PhD, and Mariano Artes, MD, Madrid, Spain

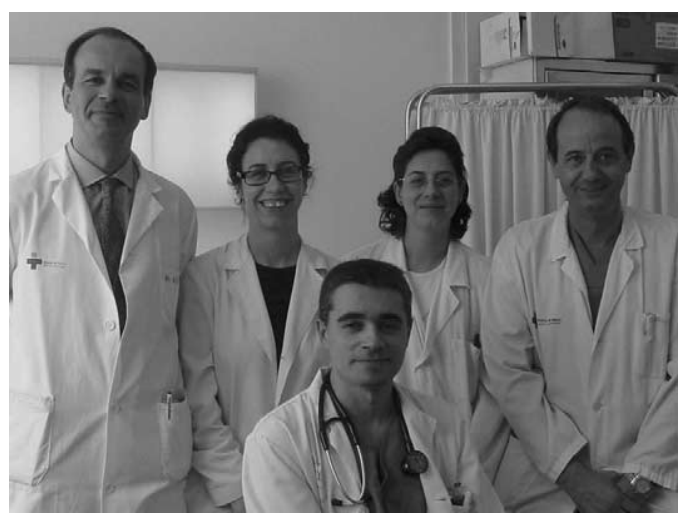

Varela, Hernández, Gámez, Córdoba, Madrigal

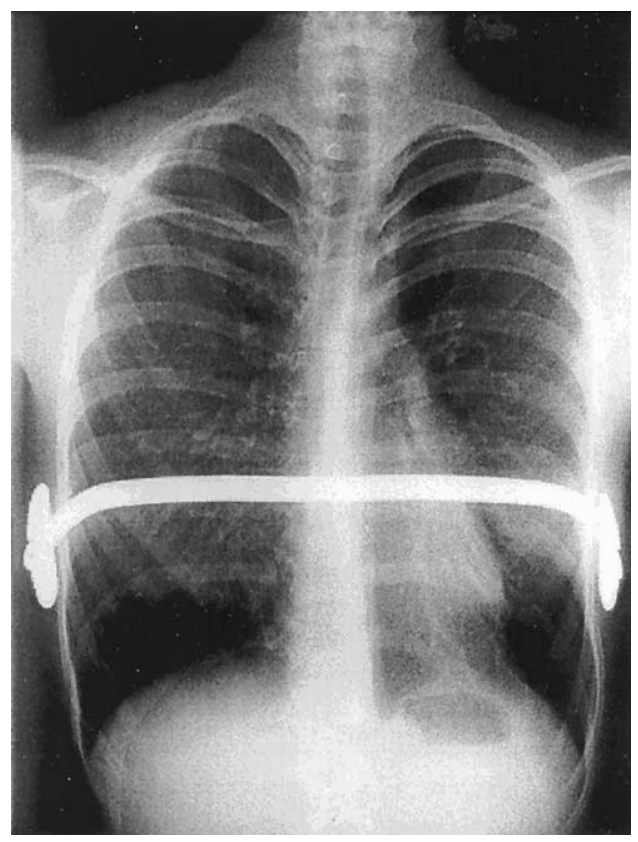

Figure 1. Chest $x$-ray film visualizing the pectus bar in its postoperative position.

under the sternum. Because this maneuver could be difficult and dangerous in older patients and in patients with severe asymmetric deformities, we prefer to advance extrapleurally under scope control, crossing over the right anterior thoracic vessels and continuing on immediately under the sternum until the clamp reaches the left selected intercostal space. Although there are surgeons who do not use the thoracoscope routinely, ${ }^{4}$ we always use it on the right side to maximize visualization of the extrapleural path. The use of the thoracoscope on the left side is not necessary because the distance you have to cover until you reach the assistant finger on the other side is so small that safety is considered. Then, as with the Nuss procedure, a tape is passed through the extrapleural tract to use as a guide; the bar is firmly knotted and pulled between the sternum and the parietal pleura. As usual, the bar is turned over until the convexity faces anteriorly and is fixed with the lateral 


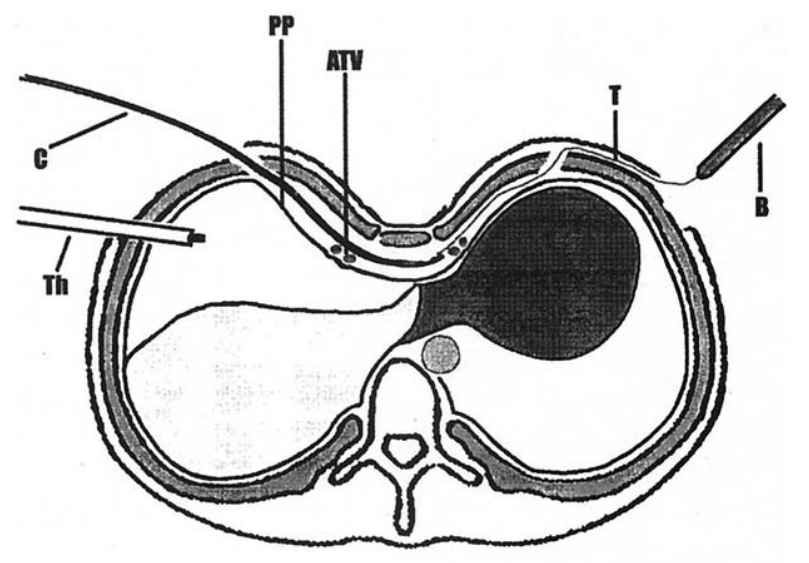

แ.H

Figure 2. Schematic view of extrapleural insertion of the pectus bar. On the right side, the lung, represented as a gray shadow, is partially collapsed. Th, Thoracoscope; $C$, clamp; PP, parietal pleura; ATV, anterior thoracic vessels; $T$, tape; $B$, Bar.

stabilizers. To secure them, we use heavy sutures around the junction between the pectus bar and the stabilizer and between the bar and the chest wall muscles (Figures 1 and 2). Also, a suture around the rib could be done on the upper side. An $8 \mathrm{~F}$ chest drainage (Pleurocath; Laboratoire Plastimed, Saint Leu la Forêt, France) is left in the right hemithorax (Figure 1).
When a new technique is being performed, strict adherence to the original described procedure is important to diminish complications, but modifications can improve the final results. In our experience this modification is safer and easier, it does not require expenditure of more time than the original operation, and blood loss continues to be minimal. If used gently, the clamp will damage neither the anterior thoracic vessels nor the parietal pleura. Placing the bar extrapleurally allows us to change to another intercostal space without opening the pleural space if the result is not as good as desired. Because the bar is safer and easier to remove extrapleurally, in an asymmetric pectus it could be possible to place it in different intercostal spaces in each hemithorax (Figure 2).

We conclude that videothoracoscopic extrapleural insertion of the Walter Lorenz Surgical bar is safe, permits correct placement, and prevents important complications.

\section{References}

1. Ravitch MM. The operative treatment of pectus excavatum. Ann Surg. 1949;129:429-44.

2. Lane-Smith DM, Gillis DA, Roy PD. Repair of pectus excavatum using a vascular graft strut. J Pediatr Surg. 1994;29:1179-82.

3. Nuss D, Kelly RE Jr, Croitoru DP, et al. A 10-year review of a minimally invasive technique for the correction of pectus excavatum. J Pediatr Surg. 1998;33(4):545-52.

4. Engum S, Rescorla F, West K, et al. Is the grass greener? Early results of the Nuss procedure. J Pediatr Surg. 2000;35(2):246-51.

5. Hebra A, Swoveland B, Egbert M, et al. Outcome analysis of minimally invasive repair of pectus excavatum: review of 251 cases. $J$ Pediatr Surg. 2000;35(2):252-8. 